\title{
UM OLHAR SOBRE A DOENÇA DE ALZHEIMER A PARTIR DO CINEMA, LITERATURA E ARTE.
}

\section{Isabela Rodrigues Barroso', Shirley Lima de Azevedo Menescal Conde², Tereza} Cristina Blasi ${ }^{3}$, Jane Beatriz Limberger ${ }^{4}$;

\section{RESUMO}

É consenso que a participação das artes criativas são benéficas para o bem estar, saúde e qualidade de vida das pessoas, além de promoverem a integração de grupos. Estas artes envolvem o cinema, a literatura, as artes plásticas, a música, entre outras modalidades, e podem ser desenvolvidas para apoiar os cuidados aos pacientes e cuidadores. No entanto, o campo das artes e da saúde é complexo e deve se adaptar as necessidades de cada grupo e ao cenário envolvido. Em tempos de pandemia por COVID-19, a arte assume uma importância ainda maior, sendo um espaço de aprendizagem a partir de atividades leves, lúdicas e divertidas, mesmo em um contexto marcado pelo isolamento social. Este artigo tem como objetivo relatar a experiência de um grupo de extensão universitária com cuidadores de pessoas com Doença de Alzheimer, por meio de artes criativas em ambientes de saúde para apoiar o bem-estar da comunidade envolvida.

Palavras-chave: Demência; Criatividade; Cuidado Centrado no Paciente.

Eixo Temático: Atenção Integral e Promoção à Saúde (AIPS).

\section{INTRODUÇÃO}

A Doença de Alzheimer (DA) é a doença neurodegenerativa mais comum, que afeta cerca de 50 milhões de pessoas em todo o mundo. A doença se dá pelo acúmulo de placas beta amiloides extracelulares e emaranhados neurofibrilares intraneuronais. Embora vários fatores genéticos causais tenham sido identificados, fatores ambientais e escolhas de estilo de vida parecem ser os principais determinantes da doença (SANTIAGO; POTASHKIN, 2021).

Portanto, precisamos de uma compreensão da natureza, escala, distribuição e determinantes da doença fornecidos pela epidemiologia, e precisamos de evidências

\footnotetext{
${ }_{1}^{1}$ Autor/Apresentador - Universidade Franciscana - isabela.barroso@ufn.edu.br

${ }^{2}$ Colaboradora - Universidade Franciscana - shirley.azevedo@ufn.edu.br

${ }^{3}$ Colaboradora - Universidade Franciscana - terezacristina@ufn.edu.br

${ }^{4}$ Orientadora - Universidade Franciscana - janebeatriz@ufn,edu.br
} 
sobre o que funciona para promover a saúde por meio de estudos de intervenção rigorosamente avaliados, que podem ir muito além do uso de medicamentos e terapias tradicionais. Além de uma crescente consciência do papel dos determinantes sociais da saúde, há um reconhecimento renovado de que saúde é mais do que a simples ausência de doença. Existem vários recursos que podem ajudar a promover uma sensação de bem-estar e até felicidade. Isso se reflete na consciência de que os determinantes do bem-estar e os determinantes da saúde se sobrepõem, mas não são idênticos, e que podem apoiar a saúde e o bem-estar (CLIFT, 2012).

Ao considerarmos as intervenções baseadas em artes criativas com grupos, precisamos ainda considerar as especificidades deste cenário. Assim, o grupo de apoio deve ser visto como um conjunto restrito de pessoas que, ligadas por constantes de tempo e espaço, e articuladas por sua mútua representação interna, se propõe de forma explicita ou implícita à realização de uma tarefa que constitui sua finalidade, interatuando para isso através de complexos mecanismos de adjudicação e assunção de papéis (SAMEA, 2008). Muitas vezes, a sobrecarga de atividades de cuidadores de pessoas com Doença de Alzheimer encontra uma válvula de escape na participação de grupos, uma vez que o compartilhamento de experiências é capaz garantir um espaço para escuta, acolhimento, interações, diálogo, e construção de saberes, visando à abertura conjunta de possibilidades de ajustamento, em busca de um novo significado do processo de cuidado (COSTA, TORGAL, GOMES, 2020).

Nessa ideia de aliviar o fardo da doença, é onde, entre outras disciplinas não médicas, a arte entra em cena, não como cura, mas como um canal que tanto facilita a expressão do desconforto, por meio do uso de técnicas diferentes; como a serena contemplação da beleza, através do olhar dos artistas. Apesar da ciência não ter conseguido anestesiar o envelhecimento, nem interromper o esquecimento, nem encapsular as experiências das pessoas em pílulas para depois recuperar as memórias, permitiu reconhecer a importância da arte como ferramenta expressiva de desconforto e meio de aceitação de si em todas as circunstâncias (MARTíNEZVÉREZ; ALBAR-MANSOA; LÓPEZ-MÉNDEZ; TORRES-VEGA, 2020). 
Neste contexto, o objetivo do presente artigo é relatar a experiência da utilização de estratégias baseadas na arte e na criatividade em um grupo de extensão para cuidadores de pessoas com Doença de Alzheimer, como estratégia de educação em saúde em tempos de pandemia por COVID-19.

\section{METODOLOGIA}

Trata-se de um relato de experiência, definido como a descrição que um autor ou uma equipe fazem de uma vivência profissional tida como exitosa ou não, mas que contribua com a discussão, a troca e a proposição de ideias para a melhoria do cuidado na saúde (UFJF, 2018).

As ações desenvolvidas durante o período de vigência do projeto de extensão (2020-2021) tiveram por objetivo transpor as dificuldades impostas pelo isolamento social, preconizado para o combate à pandemia por COVID-19, por meio da implementação de estratégias e conhecimentos que viabilizem uma educação libertadora. Para tanto, é necessário compreender e abranger as singularidades de cada sujeito, além de fazer cada momento ser notado através de levezas presentes na música, no cinema, nas artes, no olhar e no cuidado em saúde, proporcionando assim, aos cuidadores e pessoas idosas residentes atividades diferenciadas, que transformem as suas rotinas.

Em função da faixa etária dos cuidadores, as atividades de extensão estiveram restritas ao ambiente remoto, utilizando a plataforma Microsoft Teams ${ }$, para a qual cuidadores, estudantes e professores possuem cadastro prévio. As atividades foram realizadas no período de agosto de 2020 a julho de 2021, com periodicidade quinzenal, de acordo com o cronograma estabelecido em conjunto com a equipe. Como ações desenvolvidas relacionadas às artes criativas, destacamse: o cinema, quando houve a projeção do filme "Para sempre Alice" para discussão do tema Alzheimer precoce; "Espiritualidade" através de atividades da pastoral universitária, com músicas e reflexões; "Exposição fotográfica" por meio de imagens trazidas pelos cuidadores para referenciar situações de cuidado; "Talentos do grupo AMICA" onde foram trabalhadas peças de poesias, trabalhos manuais, lettering, entre outros. 


\section{RESULTADOS E DISCUSSÕES}

\section{Descrição do cenário de atividades}

O grupo AMICA (Assistência Multidisciplinar Integrada aos Cuidadores de Pessoas com Doença de Alzheimer) possui uma trajetória de mais de 15 anos de trabalho junto à cuidadores de pessoas com doença de Alzheimer. Durante a pandemia de COVID-19, os encontros do Grupo AMICA ocorreram de forma remota, por meio da plataforma digital Microsoft Teams ${ }^{\circledR}$. Através da plataforma Instagram ${ }^{\circledR}$ e WhatsApp ${ }^{\circledR}$, foram divulgadas as atividades desenvolvidas junto ao grupo. Os cuidadores envolvidos com o grupo contam com uma rede de apoio para que seja possível a participação de cada um. Os colaboradores do grupo, alunos e professores da Universidade Franciscana (UFN) e de outras instituições como a Universidade Federal de Santa Maria (UFSM), compõem essa rede de apoio, fazendo com que os encontros possam ocorrer de forma satisfatória.

\section{O cinema para discussão da doença de Alzheimer precoce}

A inserção do cinema na terapia de grupos auxilia na formação e difusão de interpretações e significados, que podem potencialmente, se transformar em novas práticas de reflexão ou de comportamento. Para inclusão do cinema, foi sugerido o filme "Para sempre Alice", cujo conflito gira em torno da gradativa perda de memória e de autonomia da protagonista por ocasião de um raro tipo de Alzheimer de causa hereditária e precoce. Os cuidadores foram instruídos a assistir o filme em um momento oportuno, para posterior discussão e exposição. Em um dos encontros, houve a discussão sobre o filme e sobre como é a aceitação da pessoa diagnosticada com a Doença de Alzheimer precoce. A exposição da atividade foi feita pelos acadêmicos envolvidos com o projeto, onde foram confeccionadas apresentações com cenas, fotos, frases e trechos do filme, e também do livro que inspirou o filme.

Foi possível identificar nas cenas que o culto aos padrões de beleza e à eterna busca pela juventude reforçam o estigma de que a maturidade representa a inércia, a estagnação de novas movimentações intelectuais, políticas ou emocionais. 
No filme, o envelhecimento vem acompanhado de uma doença degenerativa, que isola e silencia o indivíduo, sendo tratado como alguém que já morreu, ainda que permaneça vivo (GUÉRCIO, 2016). Esta percepção reforça a importãncia da manuteção de vínculos que beneficiam paciente e cuidador.

Assim como o cinema, a literatura abrange os temas discutidos em grupos de apoio, e não poderia ser diferente com o AMICA. Ao longo das atividades foram feitas diversas indicações de livros com a temática da Doença de Alzheimer, ou que expõem o cuidado como um todo.

\section{A Espiritualidade e a música como estratégia de cuidado}

A espiritualidade pode ser considerado um recurso de tratamento, o qual se ampara no aspecto emocional e motivacional, tanto para o paciente quanto para os familiares (KAMADA, et al. 2019). Da mesma forma, a música também tem o poder de auxiliar no momento do cuidado e para exercício da memória. O objetivo da música como fim terapêutico, no âmbito da Doença de Alzheimer, consiste em atingir faculdades cognitivas, emoções, memórias e pensamentos, onde a memória desse indivíduo se mantém, estabelecendo uma espécie de preservação do sentimento de identidade do sujeito. Para além, pode significar uma ampliação da existência, da estabilidade, do foco e, principalmente, ser uma via que transporte afeto por meio das emoções (PASSOS, 2021).

O grupo AMICA está diretamente ligado com o cuidado por meio da espiritualidade e da música. Ao longo dos encontros, um momento sempre esperado por todos é a participação da pastoral universitária, que a partir de canções e reflexões, propõem momentos de suma importância para o grupo. Sempre com palavras de carinho, afeto e principalmente cuidado, a pastoral faz a abertura e o encerramento de cada semestre de atividades.

\section{Minha memória afetiva: Exposição fotográfica}

Com o passar dos anos, as fotografias impressas foram sendo esquecidas por muitos, mas no grupo AMICA, elas se tornam ferramentas de cuidado. Em um dos encontros, foi solicitado aos cuidadores que apresentassem fotografias que 
referenciassem situações de cuidado, no ambiente familiar, ou no local de trabalho. Foram apresentadas belas imagens para tratar do assunto principal: A Doença de Alzheimer. No momento em que pensamos na DA, sempre nos é referida a frequência dos lapsos de memória, em que muitas vezes o paciente não lembra de certas informações, atitudes e locais. Contudo, a utilização de imagens, permite o resgate da memória perdida de maneira mais natural. Durante o encontro também foram apresentados relatos dos cuidadores com seus pacientes e familiares, onde a fotografia apareceu não apenas na forma de cuidado, mas também de forma afetiva.

A partir da experiência, foi possível estabelecer uma relação entre a fotografia e a afetividade, não apenas como mero registro da realidade, mas como vestígio de uma história que está salva em um arquivo de computador ou guardada em uma caixa de sapato e que pode ser narrada e relembrada. A fotografia nos permite ver 0 Alzheimer de outra forma e por outros ângulos, não apenas o da doença. Quando observamos fotos é quase como se pudéssemos escutar, por exemplo, o que pensam, ouvir suas histórias, conhecer suas músicas preferidas, seus gostos e atividades diárias (OLIVEIRA, 2020). Emocionou a todos o fato de conhecer além das pessoas com Alzheimer, também os demais componentes dos núcleos familiares e compreender as relações estabelecidas por estes atores.

\section{Talentos do grupo AMICA}

Durante o primeiro semestre de 2021, foram incluídos novos acadêmicos ao grupo por meio de um processo seletivo que considerou suas perspecitvas e percepções acerca do tema doença de Alzheimer. Estes acadêmicos foram de suma importância para o crescimento do grupo ao longo do semestre, em função das suas caracteristicas colaborativas e de seu entusiasmo para com as atividades desenvolvidas. No último encontro semestral, não deixamos de reconhecer suas caminhadas junto ao grupo, e propusemos uma dinâmica especial, a fim de trazer um pouco das características de cada um na atividade: "Talentos do grupo AMICA". Os acadêmicos e também os docentes envolvidos com o projeto, apresentaram seus talentos para os cuidadores presentes. Nesse momento, foram apresentados peças de teatro, poesias, trabalhos manuais, lettering, desenhos alusivos, músicas, etc. 
Nesta atividade, os acadêmicos se envolveram de maneira especial e encantaram a todos os presentes. É impotante considerar que, de uma maneira geral, os estudantes da área da saúde acabam focando somente o conteúdo acadêmico durante sua estadia na faculdade, gerando uma grande defasagem cultural, devido à falta de interesse do aluno por atividades culturais extracurriculares (PENHA et al., 2013). Ainda que em ambiente remoto, esta oficina demonstrou ser uma estratégia possível a todos os participantes do grupo, possibilitando a interação social e a manutenção do vínculo destes com a equipe, além de abrir espaços para a expressão de sentimentos e vivências.

Por ser o encontro de encerramento, foi planejada uma homenagem para os cuidadores do grupo AMICA, em que os acadêmicos fizeram cartazes respondendo a seguinte questão: "O seu cuidado significou para mim..."; Na sequência, as imagens dos estudantes segurando seus cartazes foram reunidas e compuseram um vídeo que foi compartilhado no encontro e nas redes sociais do grupo.

\section{CONCLUSÃO}

A arte é de suma importância para o crescimento pessoal de cada ser humano. Todas as formas de arte desenvolvidas junto ao grupo foram necessárias para que a disseminação de conhecimentos sobre a DA se concretizasse em um cuidado mais humanizado, carinhoso, sutil e empático. Ela nos move, une pessoas de diferentes lugares, com diferentes estilos e objetivos de vida, mas para todos 0 propósito é o mesmo: fazer da vida e do cuidado, uma arte.

\section{AGRADECIMENTOS}

Agradecemos à Pró-reitoria de Pós-graduação e Pesquisa, assim como à Universidade Franciscana pela oportunidade, ao Programa de Bolsas de Extensão (PROBEX) pelo auxílio, e aos cuidadores do grupo AMICA que estão sempre presentes para compartilhar suas experiências. 


\section{REFERÊNCIAS}

CLIFT, S. Creative arts as a public health resource: moving from practice-based research to evidence-based practice. Perspectives in Public Health, v. 132, n. 3, p. 120-127, 2012.

COSTA, M.B.A.L., AZEVEDO, M.J.T., TORGAL, M.C.P., GOMES, J.C.R. Grupos de ajuda mútua com cuidadores informais de pessoas com demência: empowerment do cuidado. Rev. Interinst. Bras. Ter. Ocup. Rio de Janeiro, v.4, n.2, p.158-177, 2020.

GÜÉRCIO, N. H. A arte de perder: os silenciamentos do mal de Alzheimer na maturidade feminina protagonista em para sempre alice. Revista de Comunicação da Universidade Católica de Brasília, v. 9, n. 2, p. 221-35, 2016.

KAMADA, Márcio et al. O papel da espiritualidade no enfrentamento da doença de Alzheimer. Revista da Sociedade Brasileira de Clínica Médica, v. 17, n. 1, p. 21 24, 2019.

MARTÍNEZ-VÉREZ, M.V.; ALBAR-MANSOA, P.J.; LÓPEZ-MÉNDEZ, L.; TORRESVEGA, S. Cápsulas de arte: memoria frente al Alzheimer. Interface (Botucatu). v.24, n.e200128, 2020.

OLIVEIRA, L.H.P. Uma narrativa fotobiográfica diante do Alzheimer. [manuscrito] / Larissa Helena Pereira De Oliveira. - 2020. Oli60 f.: il.: color..

PASSOS, H. et al. A música como agente terapêutico no tratamento da Doença de Alzheimer. Revista Psicologia em Pesquisa, v. 15, n. 1, 2021.

PENHA, L.; DEZAN JUNIOR, E.; PEREIRA, S.; CRUZ, R.; LOUREIRO, C.; BUENO, L. O-124G - Promoção de cultura na FOA através do Show de Talentos. Archives Of Health Investigation, v. 2, 30 dez. 2013.

SAMEA, M.. O dispositivo grupal como intervenção em reabilitação: reflexões a partir da prática em terapia ocupacional. Revista de Terapia Ocupacional da Universidade de São Paulo, v. 19, n. 2, p. 85-90, 2008.

SANTIAGO, J. A .; POTASHKIN, J.A. O impacto das comorbidades da doença na doença de Alzheimer. Frontiers in Aging Neuroscience , v. 13, p. 38, 2021.

UNIVERSIDADE FEDERAL DE JUIZ DE FORA. Instrutivo para elaboração de relato de experiência. Instituto de Ciências da Vida. 2018. 